Please do not remove this page

RMIT

UNIVERSITY

\title{
Fire structural resistance of basalt fibre composite
}

Bhat, T.; Chevali, V.; Liu, X.; Feih, S.; Mouritz, A.

https://researchrepository.rmit.edu.au/esploro/outputs/9921862051901341/filesAndLinks?institution=61RMIT_INST\&index=null

Bhat, T., Chevali, V., Liu, X., Feih, S., \& Mouritz, A. (2015). Fire structural resistance of basalt fibre composite. Composites Part A: Applied Science and Manufacturing, 71, 107-115.

https://doi.org/10.1016/j.compositesa.2015.01.006

Document Version: Accepted Manuscript

Published Version: https://doi.org/10.1016/j.compositesa.2015.01.006

Repository homepage: https://researchrepository.rmit.edu.au

(C) 2015 Elsevier Ltd.

Downloaded On 2023/04/26 22:38:35 +1000

Please do not remove this page 
Thank you for downloading this document from the RMIT Research Repository.

The RMIT Research Repository is an open access database showcasing the research outputs of RMIT University researchers.

RMIT Research Repository: http://researchbank.rmit.edu.au/

\section{Citation:}

Bhat, T, Chevali, V, Liu, X, Feih, S and Mouritz, A 2015, 'Fire structural resistance of basalt fibre composite', Composites Part A: Applied Science and Manufacturing, vol. 71, pp. 107-115.

See this record in the RMIT Research Repository at:

https://researchbank.rmit.edu.au/view/rmit:29869

Version: Accepted Manuscript

Copyright Statement: (c) 2015 Elsevier Ltd. This work is licensed under a Creative Commons Attribution-NonCommercial-NoDerivatives 4.0 International License.

Link to Published Version:

http://dx.doi.org/10.1016/j.compositesa.2015.01.006

\section{PLEASE DO NOT REMOVE THIS PAGE}




\section{Accepted Manuscript}

Fire structural resistance of basalt fibre composite

T. Bhat, V. Chevali, X. Liu, S. Feih, A.P. Mouritz

PII:

S1359-835X(15)00017-2

DOI: http://dx.doi.org/10.1016/j.compositesa.2015.01.006

Reference: JCOMA 3819

To appear in:

$$
\text { Composites: Part A }
$$

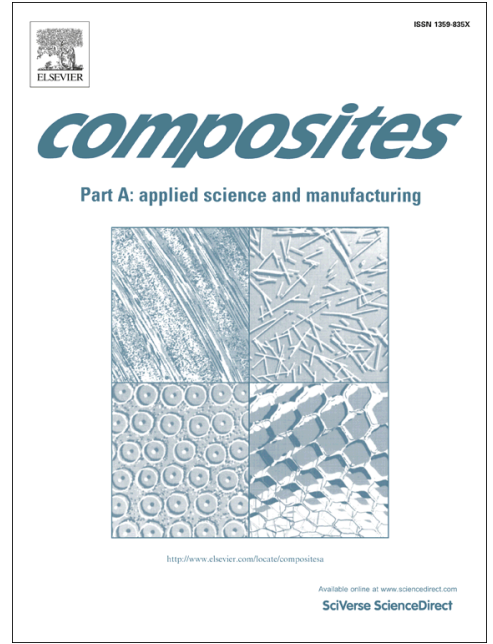

Received Date:

9 July 2014

Revised Date:

6 January 2015

Accepted Date:

10 January 2015

Please cite this article as: Bhat, T., Chevali, V., Liu, X., Feih, S., Mouritz, A.P., Fire structural resistance of basalt fibre composite, Composites: Part A (2015), doi: http://dx.doi.org/10.1016/j.compositesa.2015.01.006

This is a PDF file of an unedited manuscript that has been accepted for publication. As a service to our customers we are providing this early version of the manuscript. The manuscript will undergo copyediting, typesetting, and review of the resulting proof before it is published in its final form. Please note that during the production process errors may be discovered which could affect the content, and all legal disclaimers that apply to the journal pertain. 


\title{
FIRE STRUCTURAL RESISTANCE OF BASALT FIBRE COMPOSITE
}

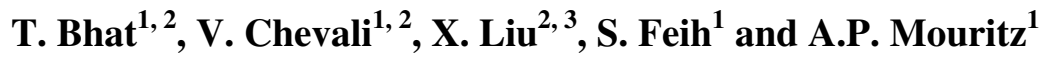 \\ ${ }^{1}$ Sir Lawrence Wackett Aerospace Research Centre, School of Aerospace, Mechanical and \\ Manufacturing Engineering, RMIT University, Melbourne, VIC 3001, Australia \\ ${ }^{2}$ Cooperative Research Centre for Advanced Composite Structures Ltd (CRC-ACS), \\ 1/320 Lorimer Street, Port Melbourne, VIC 3027, Australia \\ ${ }^{3}$ Advanced Composite Structures Australia Pty Ltd, \\ 1/320 Lorimer Street, Port Melbourne, VIC 3207, Australia
}

Corresponding author:

Adrian P. Mouritz

Tel: +61 399256269

Fax: +61399256108

e-mail: adrian.mouritz@ rmit.edu.au

\section{ABSTRACT}

Basalt fibres are emerging as a replacement to E-glass fibres in polymer matrix composites for selected applications. In this study, the fire structural resistance of a basalt fibre composite is determined experimentally and analytically, and it is compared against an equivalent laminate reinforced with E-glass fibres. When exposed to the same radiant heat flux, the basalt fibre composite heated up more rapidly and reached higher temperatures than the glass fibre laminate due to its higher thermal emissivity. The tensile structural survivability of the basalt fibre composite was inferior to the glass fibre laminate when exposed to the same radiant heat flux. Tensile softening of both materials occurred by thermal softening and decomposition of the polymer matrix and weakening of the fibre reinforcement, which occur at similar rates. The inferior fire resistance of the basalt fibre composite is due mainly to higher emissivity, which causes it to become hotter in fire. 
Keywords: A. Polymer-matrix composites (PMCs); B. Thermomechanical; C. Analytical modelling; Basalt fibre

\section{INTRODUCTION}

There is growing interest in reinforcing polymer matrix composites with mineral basalt fibres because of their moderate cost, high stiffness and strength, excellent corrosion and oxidation resistance, and heat resistance and thermal stability [1]. Basalt is the generic term for solidified volcanic lava, and it can be melt extruded into continuous filaments using a process similar to glass fibre production. Several types of basalt fibre are commercially available, with slightly different properties depending on the chemical composition of the basalt rock and the process conditions used to extrude the molten basalt into fibres. The stiffness and strength properties of basalt fibre is higher than E-glass fibre, which is the most common reinforcement for polymer matrix composites [1,2]. The Young's modulus of basalt fibre (100 to $110 \mathrm{GPa}$ depending on the chemical composition and source of the basalt rock) is much higher than E-glass (76 GPa). The tensile failure stress of basalt fibre (4.15 - 4.8 GPa) is also greater than E-glass (3.45 GPa). Basalt fibre is resistant to most chemicals, and is less prone to damage from alkali solutions and water than E-glass [3]. Because of these properties, basalt fibre is being used or considered as a replacement to E-glass for several applications, including wind turbine blades, automotive components, and reinforcement in civil structures and concrete [1].

There is growing interest in using basalt fibre for high temperature applications. Basalt fibre is slightly inferior, similar or superior to E-glass fibre depending upon the specific thermal, physical or high temperature property [1,3-5]. Both basalt and glass fibres have similar thermal conductivity values (typically in the range of $0.031-0.038 \mathrm{~W} /(\mathrm{m} . \mathrm{K})$ ) and specific heat 
capacity values $\left(\sim 840-860 \mathrm{Jg}^{-1} \mathrm{~K}^{-1}\right)$, which indicates they provide a similar level of heat insulation. Basalt fibre is superior to E-glass for high temperature properties such as elastic modulus at elevated temperature [4], operating temperature limit $\left(\sim 650^{\circ} \mathrm{C}\right.$ for basalt compared to $\sim 460^{\circ} \mathrm{C}$ for E-glass), and higher softening temperature $\left(1050^{\circ} \mathrm{C}\right.$ for basalt and $600^{\circ} \mathrm{C}$ for E-glass). For these reasons basalt is being used or considered for use in high temperature applications, such as in hot gas filtration systems and fire resistant electrical cable systems [1]. However, other thermal properties of basalt are inferior to E-glass, including lower creep onset temperature [5] and tensile strength at elevated temperature.

Despite the high temperature applications of basalt fibre, the fire resistance of basalt reinforced polymer composites is not known. It is not known whether the higher stiffness, operating temperature and softening temperature of basalt fibre translates into superior fire resistance when used as the reinforcement to polymer composite materials. A large body of research has been published on the fire structural resistance of E-glass reinforced composites under compressive and tensile loading [7-19]. Similarly, the fire resistance of carbon fibre laminates have also been studied [20]. However, the structural response and failure of basalt fibre composites under combined loading and one-sided heating by fire has not been investigated.

This study investigates the fire structural resistance of a basalt fibre reinforced polymer composite. The fire resistant properties of a woven basalt fibre composite are experimentally determined using fire structural tests involving combined tensile loading and one-sided unsteady-state heating representative of one possible fire. These tests provide new insights into the mechanical integrity and survivability of basalt fibre composite structures in fire. The effects of the applied tensile stress and the radiant heat flux on the structural survivability of 
basalt fibre composite are assessed. In addition, the mechanisms controlling the tensile softening and failure of basalt fibre composite in fire are investigated by residual property testing of basalt fibre tows following exposure to high temperature. The fire structural survivability of the basalt fibre composite is compared against an equivalent E-glass fibre composite to assess their relative performance. This comparison is performed because of the growing interest in replacing glass fibre composites with basalt fibre composites in certain applications [1].

\section{MATERIALS \& EXPERIMENTAL METHODS}

\subsection{Composite Materials}

Basalt fibre composite was produced for high temperature and fire structural testing using woven basalt fabric and vinyl ester resin. The basalt fabric was plain woven by the supplier (Zhejiang GBF Fiber Co. Ltd.) using 300 tex tows to an areal density of $350 \mathrm{~g} / \mathrm{m}^{2}$. The basalt fibres had an average diameter of $12.7 \mu \mathrm{m}$ (standard deviation of $1.4 \mu \mathrm{m}$ ). The basalt fabric was stacked so the warp tows were aligned to create a cross-ply fibre pattern. Vinyl ester resin (SPV 1349 Nuplex Composites) was infused into the fabric at room temperature using the vacuum bag resin infusion (VBRI) process. Following infusion, the vinyl ester matrix was gelled and partially cured under ambient conditions $\left(23^{\circ} \mathrm{C}, 50 \% \mathrm{RH}\right)$ and then post-cured at $80^{\circ} \mathrm{C}$ for two hours. The fibre volume content of the basalt composite was determined to be 53\% using the ASTM D-3171 burn-off technique.

The fire resistant properties of the basalt composite were compared against an equivalent glass fibre composite. The composite was reinforced with plain woven E-glass fabric (800 $\mathrm{g} / \mathrm{m}^{2}$ ) with an average fibre diameter of $12.2 \mu \mathrm{m}$ (standard deviation of $1.5 \mu \mathrm{m}$ ). The diameter of the basalt and E-glass fibres were similar (within $0.5 \mu \mathrm{m}$ ). The glass fibre composite was 
made with the same vinyl ester resin and using the same VBRI process and cured under the same conditions as the basalt fibre composite. The fibre stacking sequence of the glass fibre laminate was also cross-ply and the fibre volume content was $55 \%$. The only significant difference between the basalt and glass fibre composites was the type of reinforcement.

\subsection{High Temperature Property Testing of Basalt Fibre Tows and Composites}

\subsubsection{Mechanical Testing of Fibre Tows}

The tensile properties of basalt fibre tows were measured following exposure to high temperature to determine the fibre softening rate and strength loss. This information is used to understand the fire structural resistance of the basalt composite under tensile loading. The tows (300 tex) used for testing were the same as those in the woven basalt fabric used to reinforce the polymer composite. The basalt tows were heated to temperatures between 150 and $650^{\circ} \mathrm{C}$ for different times up to two hours. The tows were then cooled to room temperature and their residual tensile strength was measured at $20^{\circ} \mathrm{C}$. The tensile failure load was measured by loading a basalt tow with a gauge section of $150 \mathrm{~mm}$ at an extension rate of $2 \mathrm{~mm} / \mathrm{min}$ to failure using a $10 \mathrm{kN}$ load capacity Instron machine (Model: 4501). The tensile strength value of the basalt tows measured at high temperature was similar to that measured at room temperature after thermal treatment. Table 1 shows the residual failure stress of basalt tows measured at $20^{\circ} \mathrm{C}$ following heating at several temperatures. Also given in the table is the failure stress of the basalt tows measured in-situ at elevated temperature. The bundle strength at high temperature was measured using the procedure described by Feih et al

[15]. Table 1 shows that the basalt tow strengths measured at high temperature and at $20^{\circ} \mathrm{C}$ following high temperature exposure are very similar (within about 5\%). It appears that any weakening of the basalt tow that occurs at high temperature is 'locked-in' and does not change when cooled slowly to room temperature. For convenience, therefore, the tensile 
strength of the tows was measured at $20^{\circ} \mathrm{C}$ after thermal treatment rather than in-situ at high temperature.

For comparison, the tensile failure load of E-glass tows (280 tex) were measured for the same heat treatment and test conditions as the basalt tows. Feih et al. [18] have shown that any weakening of E-glass fibre at high temperature is also 'locked-in' when cooled to room temperature. Therefore, similar to the basalt tows, the residual tensile properties of the Eglass tow was measured at $20^{\circ} \mathrm{C}$ following heat-treatment at different temperature and heating times.

Five tows of basalt and E-glass were tested at $20^{\circ} \mathrm{C}$ following exposure to identical temperature and heating time conditions to determine the scatter in the failure load.

\subsubsection{Mechanical Testing of Composites}

The tensile properties of the basalt and glass fibre composites were measured at temperatures between 20 and $300^{\circ} \mathrm{C}$. The tensile tests were performed according to ASTM D3039 using composite coupons with a gauge length of $150 \mathrm{~mm}$, width of $25 \mathrm{~mm}$, and thickness of $4 \mathrm{~mm}$. To achieve the same thickness, the basalt and glass fibre composites contained 18 and 7 plies of woven fabric, respectively. A larger number of basalt plies was needed because they were thinner than the glass plies. Despite this difference, the fibre volume contents of the two composites were virtually the same. The tensile tests were performed at a loading rate of 2 $\mathrm{mm} / \mathrm{min}$ inside an oven attached to a $100 \mathrm{kN}$ MTS machine. The basalt and glass fibre composites were loaded in the $0^{\circ}$ (warp) tow direction at different temperatures to failure. Three samples were tested at different temperatures to assess the variability in the measured tensile properties. The ends of the tensile specimens were tabbed, and this region was 
clamped via pressure grips to the MTS machine. Failure always occurred within the gauge region of the samples, and never within the tabbed region.

\subsection{Fire Structural Testing of Composites}

Small-scale fire structural tests were performed on the basalt and glass fibre composites to assess their fire resistance. This test is designed to replicate the condition of a tensile-loaded plate exposed to one-side constant radiant heat flux representative of a possible fire scenario. The test basically involves subjecting a rectangular composite sample to combined tensile loading and one-sided unsteady-state radiant heating, as shown schematically in Figure 1. The distance between the radiant heating source and the composite sample was set at $25 \mathrm{~mm}$. The rectangular-shaped composite test samples were $600 \mathrm{~mm}$ long, $50 \mathrm{~mm}$ wide and $9 \mathrm{~mm}$ thick. The basalt and glass fibre composites contained 42 and 15 plies, respectively to have the same thickness of $9 \mathrm{~mm}$. The fibre volume fraction of both materials was very similar $(\sim 0.53)$.

The fire structural test involved loading the composite sample along the $0^{\circ}$ fibre (or warp) direction at a constant tensile stress between $20 \%$ and $80 \%$ of the failure stress at room temperature. The average failure stress was $460 \mathrm{MPa}$ for the basalt fibre composite and 470 $\mathrm{MPa}$ for the glass fibre composite at $20^{\circ} \mathrm{C}$. While under constant tensile stress, a $100 \mathrm{~mm}$ long section of the composite sample was exposed to an initial incident radiant heat flux of 25 or $50 \mathrm{~kW} / \mathrm{m}^{2}$. The heat flux was calibrated before testing using a Medtherm heat flux transducer (Model no. 32-10SB-10-197-21633). The sample was held under constant stress and one-sided radiant heating until failure, and the stress rupture time was used to define the fire structural resistance. Two samples were tested for each heat flux and tensile stress 
condition. A full description of the fire structural test procedure and apparatus is given in Ref. [18].

\section{FIRE STRUCTURAL ANALYSIS OF BASALT AND GLASS FIBRE COMPOSITES}

In addition to fire structural testing, thermal-mechanical modelling was used to compute the fire structural resistance of the basalt fibre composite and compares its performance against the E-glass composite. The model basically consists of two analytical components: thermal analysis to compute the through-thickness temperatures of the composite and mechanical analysis to calculate the reduction in strength caused by heating from the fire. A full description of the model for E-glass composites is provided by Feih et al. [18], and it is applied here for the first time to a basalt fibre composite.

A model developed by Henderson et al. [22] was used to calculate the through-thickness temperatures of the composites when exposed to one-sided heating by fire. The governing equation for calculating the temperature at any location and time through the composite is expressed as:

$\rho(T) C_{p}(T) \frac{\partial T}{\partial t}=\frac{\partial}{\partial x}\left(k(T) \frac{\partial T}{\partial x}\right)-\left(Q+h_{C}-h_{G}\right) \frac{\partial \rho}{\partial t}-\dot{m}_{G} C_{G} \frac{\partial T}{\partial t}$

The three terms on the right hand side of Eq. (1) relate to the three key processes controlling the temperature of a composite material exposed to fire: heat conduction, resin decomposition and volatile convection, respectively. The first term considers heat conduction from the fire exposed surface through-the-thickness of the composite. The resin decomposition term accounts for the heat which is generated (exothermic) or absorbed (endothermic) by pyrolysis 
of organic materials within the composite. The volatile convection term accounts for the cooling effect caused by hot decomposition gases when they diffuse from the decomposition zone in the composite to the fire exposed surface.

In Eq (1), $T, t$ and $x$ are the temperature, time and distance below the fire-exposed surface, respectively. $\rho$ is the instantaneous density of the composite material, which decreases when the matrix decomposes. $M_{g}$ is the mass flux of volatiles. $h_{\mathrm{c}}$ and $h_{\mathrm{G}}$ are the enthalpies of the composite and evolved gas, respectively. $Q$ is the endothermic decomposition energy of the polymer matrix. $C_{p}$ and $k$ are the specific heat and thermal conductivity of the composite which are determined using rule-of-mixtures:

$\mathrm{k}(\mathrm{T})=\mathrm{f}_{\text {virgin }} \mathrm{k}_{\text {virgin }}+\mathrm{f}_{\text {char }} \mathrm{k}_{\text {char }}$

$C_{p}(T)=f_{\text {virgin }} C_{P, \text { virgin }} \dashv f_{\text {char }} C_{P, \text { char }}$

$f$ is the volume fraction of the virgin or fully decomposed (charred) composite.

The polymer matrix is assumed to thermally decompose via a single-stage reaction process which can be defined by the Arrhenius rate equation:

$\left[\frac{\partial \rho}{\partial t}\right]=-\left(\rho_{v}-\rho_{\text {char }}\right)\left[\frac{\rho-\rho_{\text {char }}}{\rho_{v}-\rho_{\text {char }}}\right]^{n} \cdot A e^{-Q / R T}$

The order of reaction, $n$, is assigned a value of unity in this study. The mass-loss kinetic (Arrhenius) parameters $(A, Q, n)$ for the vinyl ester resin used as the matrix phase to the basalt and glass fibre composites was determined by thermogravimetric analysis. 
The unheated surface of the composite is assumed to have the thermal boundary condition defined by:

$-\left.k_{x} \frac{\partial T}{\partial x}\right|_{x=t_{C}}=0$

where $t_{c}$ is the thickness of the composite.

Once the through-thickness temperatures have been calculated for increasing increments of heating time using the thermal model (Eq. 1), it is then possible to compute the residual tensile strength of the composite based on these temperatures. The tensile strength of a hot, decomposing composite is determined by the through-thickness variations in the strengths of the matrix and fibres. The strength dependency of the matrix and fibres on the temperature must be determined experimentally under isothermal conditions.

The matrix strength is related to the temperature using [14]:

$$
\sigma(T)=\left(\frac{\sigma_{O}+\sigma_{R}}{2}-\frac{\sigma_{o}-\sigma_{R}}{2} \tanh \left(\Phi\left(T-T_{g}\right)\right)\right) R_{r c}(T)^{n^{* \prime}}
$$

$\Phi$ is the original strength of the composite, which can be calculated using laminate theory or measured. $\Phi$ is the strength of the composite when the polymer matrix has fully softened. $T_{g}$ is the glass transition temperature of the composite. $q$ defines the breadth of the strengthtemperature curve, and this must be measured. $R_{r c}(T)$ accounts for softening caused by endothermic decomposition of the polymer matrix [18].

The reduction in the temperature strength of the basalt and glass fibres within a composite exposed to fire is assumed to be related to both the temperature $(T)$ and heating time $(t)$ according to the relationship [18]: 
$\left.c_{f}(t, T)=c_{f(0)}-c_{\text {loss }}(T) \tanh \mid k_{f}(T) t\right\rfloor$

where $\left.\Phi_{0}\right)$ is the original fibre strength, $\Phi_{s s}(T)$ is the strength loss at elevated temperature which is calculated using:

$\sigma_{\text {loss }}(T)=\frac{c_{f(0)}}{2}+\frac{c_{f(0)} \cdot \tanh \left\lfloor p_{f}\left(T-T_{50 \%}\right)\right\rfloor}{2}$

$T_{50 \%}$ is the temperature at which the fibre loses $50 \%$ of the original strength. $p_{f}$ is an empirically derived curve fitting constant.

$k_{f}(T)$ in $\mathrm{Eq}(7)$ defines the strength loss rate, which is determined using:

$k_{f b}(T)=k_{1} e^{k_{2} T}$

where $k_{1}$ and $k_{2}$ are constants dependent on the fibre type.

Eqs 6 and 7 are used to calculate the effect of temperature on the residual strengths of the matrix and fibres at any location through-the-thickness of a composite exposed to fire. A modified rule-of-mixtures equation is used to determine the strength at any location through the composite based on the residual strengths of the matrix and fibre:

$C_{(j)}(T, t)=\Phi_{L T}(T) V_{f} C_{f b(j)}(T, t) \dashv\left(1-V_{f}\right) C_{m(j)}(T)$ with $\Phi_{L T} \leq 1$

$\Phi_{\mathrm{LT}}$ is a parameter to account for the stress transfer efficiency between the fibres and matrix as the polymer softens with increasing temperature, and this must be measured. 
Once, the strength values at various through-thickness locations are computed using Eq (10), the bulk tensile strength ( $\sigma$ can be determined for increasing increments of heating time using Simpson integration technique:

$$
\sigma=\frac{1}{\mathrm{t}_{\mathrm{c}}} \int_{0}^{\mathrm{t}_{\mathrm{c}}} \sigma(\mathrm{x}) \mathrm{dx}
$$

where:

$$
\int_{0}^{t_{c}} \sigma(x) d x=\frac{t_{c}}{3 m}\left[\sigma\left(x_{0}\right)+4 \sigma\left(x_{1}\right)+2 \sigma\left(x_{2}\right)+\ldots+2 \sigma\left(x_{y-2}\right)+4 \sigma\left(x_{y-1}\right)+\sigma\left(x_{y}\right)\right]
$$

In Eq. (12), $m$, defines an even number of points where the local strength values were calculated and was set at 50 in this study.

When the residual tensile strength of the composite is reduced to the applied tensile stress, then the laminate is assumed to fail. In this paper, the time taken for the residual strength to drop below the applied stress is taken to be the rupture time.

\section{RESULTS AND DISCUSSION}

\subsection{Thermal Response of Basalt Composite to Fire}

The temperature rise to the basalt and glass fibre composites when exposed to the heat fluxes of 25 and $50 \mathrm{~kW} / \mathrm{m}^{2}$ are compared in Figures 2 and 3. The data points show temperatures measured using thermocouples attached to the hot (heat-exposed) and cold (back) surfaces of the composites. Thermocouples were also located at the mid-thickness point of the composites to record the internal temperature. Multiple tests were performed on both composites, and the variability in the measured temperatures between tests was less than $20^{\circ} \mathrm{C}$. Exposing the composites to the lower heat flux of $25 \mathrm{~kW} / \mathrm{m}^{2}$ caused an unsteady-state rise in temperature until eventually near-thermal equilibrium was reached. Neither the basalt 
or glass fibre composites ignited when exposed to the heat flux of $25 \mathrm{~kW} / \mathrm{m}^{2}$. At the higher heat flux of $50 \mathrm{~kW} / \mathrm{m}^{2}$, the heated surface temperature of the basalt fibre composite spiked due to ignition of the front face at around $675^{\circ} \mathrm{C}$. At the same heat flux, however, the glass fibre laminate did not ignite, even after long-term heat exposure.

The basalt fibre composite heated more rapidly and reached a higher temperature than the glass fibre composite. The maximum temperature reached by the basalt fibre composite when exposed to the heat fluxes of 25 and $50 \mathrm{~kW} / \mathrm{m}^{2}$ was about 540 and $700^{\circ} \mathrm{C}$, respectively, which are significantly higher than the respective temperatures of $\sim 430$ and $640^{\circ} \mathrm{C}$ reached by the glass fibre composite. The basalt fibre composite became hotter because its emissivity $(\mathcal{E} \sim$ 0.92 at $\left.20^{\circ} \mathrm{C}\right)$ is higher than the glass fibre composite $\left(\mathcal{E} \sim 0.65\right.$ at $\left.20^{\circ} \mathrm{C}\right)$. The emissivity values were experimentally measured at room temperature using a thermal infrared camera. It is expected that the emissivity values will change with increasing temperature, although this was not measured due to difficulties in getting a direct line-of-sight between the IR camera and composite samples during fire structural testing. The higher emissivity caused the basalt fibre composite to reach a sufficiently high temperature and decomposition rate that it ignited and burnt at the heat flux of $50 \mathrm{~kW} / \mathrm{m}^{2}$. Ignition occurs when the mass flux of flammable volatiles released by a decomposing material reaches a critical level. Ignition of the basalt fibre composite indicates this material decomposed faster and released more volatiles than the glass fibre laminate, and this was due to its higher temperature when exposed to $50 \mathrm{~kW} / \mathrm{m}^{2}$.

Figures 2 and 3 show the middle and back-face temperatures of the basalt fibre composite also increased at a faster rate than the glass fibre laminate. The thermal conductivity $(k)$ and specific heat capacity $\left(C_{p}\right)$ values for basalt fibres $\left(k=0.031-0.038 \mathrm{~W} / \mathrm{m} . \mathrm{K} ; C_{p}=860 \mathrm{~J} / \mathrm{kg} . \mathrm{K}\right)$ and E-glass fibres $\left(k=0.034-0.040 \mathrm{~W} / \mathrm{m} . \mathrm{K} ; C_{p}=840 \mathrm{~J} / \mathrm{kg} . \mathrm{K}\right)$ are very similar. This reveals 
that the higher internal and back surface temperature of the basalt fibre composite is not due to faster heat transfer through this material. Instead, the faster heat-up rate within the basalt composite is attributed mostly to its higher temperature at the hot surface resulting from its higher emissivity.

The solid curves in Figures 2 and 3 show the calculated temperature rise at the surfaces and middle of the composites. The temperatures were calculated using the thermal model described in Section 3, which was solved using the property data given in Table 2. To date, this model has only been used to calculate the temperature in glass fibre laminates exposed to fire $[10,11,14-20,22]$. It has not been used to predict the temperature of other types of fibrepolymer composites, including basalt fibre laminates. The curves in Figures 2 and 3 show that the calculated temperatures were in good agreement with the measured temperatures for the basalt fibre composite except for when the material ignited which caused the computed temperature values to be too low. Agreement between the calculated and measured temperatures for the glass fibre laminate is also good.

\subsection{Mechanical Response of Basalt Composite to Fire}

One-sided radiant heating caused both the basalt and glass fibre composites to progressively deform and soften to the point when they failed under tensile loading. Figure 4 shows examples of the axial extension - heat exposure time response of the basalt and glass fibre composites over the course of tensile fire structural tests. Deformation extension curves are shown for the composites tested at high (80\%) and low (20\%) tensile stress levels while exposed to one-sided radiant heating at the heat fluxes of 25 and $50 \mathrm{~kW} / \mathrm{m}^{2}$. Figure 4 also presents a schematic curve showing the key processes causing the two composites to deform under combined tensile loading and one-sided heating. The curves are characterised by an 
initial quasi-linear increase in extension with heating time, and this was due to the combined effects of thermal expansion of the composite and thermal softening of the polymer matrix. The thermal expansion coefficient of basalt fibre $\left(8 \times 10^{-6} \mathrm{~K}^{-1}\right)$ is greater than E-glass fibre $\left(5.4 \times 10^{-6} \mathrm{~K}^{-1}\right)$, and this together with the higher matrix softening rate (because of its faster heating rate) would account for the basalt fibre composite initially elongating more rapidly than the glass fibre laminate. The curves for both composites have an inflection point, beyond which the extension rises at an increasing rate with heating time. The inflection point corresponds to the onset of fibre/tow failures near the heated surface which causes the composites to become more compliant. The extension rate then rises rapidly due presumably to progressive failure of an increasing number of fibres/tows from the heated to cooler surfaces of the composites. Progressive failure occurs earlier and more rapidly with the basalt fibre composite, indicating its tensile structural survivability in fire is inferior to the glass fibre composite.

Figure 5 shows the effect of applied tensile stress on the rupture times of the basalt and glass fibre composites when exposed to the heat fluxes of 25 and $50 \mathrm{~kW} / \mathrm{m}^{2}$. The rupture time is the duration that the composite can withstand the applied tensile stress before failure when exposed to the heat flux. The data points show the experimentally measured failure times and, as expected, for both composites these increased when the applied stress and/or heat flux were reduced. The rupture times were much shorter for the basalt composite, which is indicative of inferior fire resistance under tensile loading.

The curves in Figure 5 were calculated using the thermal-mechanical model. The material property data used to solve the model is provided in Table 2 . The model was developed specifically to predict the tensile softening of glass fibre laminates in fire, although the good 
agreement between the calculated and measured failure times for the basalt composites shows it also works well with this material.

\subsection{Softening Mechanisms of Basalt Composite in Fire}

Tensile rupture of the basalt and glass fibre composites in fire is due to several temperature dependent softening processes, which are given in Figure 6. In order of increasing temperature these are thermal softening of the polymer matrix due to the 'glassy-to-rubbery' transformation close to the glass transition temperature $\left(T_{g}\right)$, heat-induced delamination and matrix cracking, decomposition of the polymer matrix, and weakening and failure of the fibre reinforcement.

The modelling revealed that softening of both the basalt and glass fibre composites under high tensile stress $(\geq 300-350 \mathrm{MPa})$ and short rupture time ( $\leq 100 \mathrm{~s})$ conditions was dominated by thermal softening of the polymer matrix above $T_{g}$, as indicated in Figure 5 . The thermal softening behaviour of the basalt and glass composites due to the glass transition of the vinyl ester matrix is shown in Figure 7. The tensile strengths of the composites were determined under iso-thermal conditions between $20^{\circ} \mathrm{C}$ and $300^{\circ} \mathrm{C}$, which is just below the decomposition temperature for the vinyl ester matrix [11]. Figure 7 shows the tensile strength of both composites fell by $30-40 \%$ over a similar temperature range (between $80-150^{\circ} \mathrm{C}$ ) due to the glass transition of the vinyl ester matrix. DMTA measurements revealed that the glass transition temperature of the vinyl ester is $120^{\circ} \mathrm{C}$, as defined by a $50 \%$ reduction to the storage modulus from the room temperature value [15]. The tensile strengths were reduced by the loss in stress transfer efficiency between the load-bearing basalt or glass fibres and soft polymer matrix. The softening behaviour occurred over the same temperature range for both composites, although the basalt laminate experienced a greater loss in strength. This could 
account for the greater strength loss when the basalt fibre composite was subjected to high tensile stress while exposed to radiant heating.

Delamination and matrix cracks were observed in both the basalt and glass fibre composites when heated above $\sim 150-200^{\circ} \mathrm{C}$, with no significant difference in the amount of cracking between the two materials. Thermogravimetric analysis (TGA) was performed on the two composites and the neat vinyl ester used as the matrix phase to determine whether the fibre reinforcement affected the decomposition behaviour. TGA was performed on these materials in air at a heating rate of $10^{\circ} \mathrm{C} / \mathrm{min}$ using a Perkin-Elmer TGA7 instrument. Figure 8 shows the TGA curves for the materials were similar, with decomposition of the vinyl ester matrix occurring between 350 and $450^{\circ} \mathrm{C}$, and oxidation of the residual carbonaceous char between $\sim 450$ and $550^{\circ} \mathrm{C}$. The decomposition rates of the basalt and glass fibre composites were very similar, although the basalt material experienced a small mass loss (under a few percent) between $\sim 150$ and $450^{\circ} \mathrm{C}$ which was less significant for the glass fibre composite. The similarly in the TGA results between the two composites and with the vinyl ester resin suggests that the basalt fibres did not accelerate significantly the matrix decomposition rate.

The modelling revealed that at relatively low tensile stresses (under 300-350 MPa) and consequently long failure times (above $\sim 100 \mathrm{~s}$ ) the failure of the basalt and glass fibre composites was due to both matrix softening and fibre weakening, with the loss in fibre strength being the dominant process controlling the rupture time. The effects of temperature and heating time on the residual tensile failure load of the basalt and glass fibres used in the composites are compared in Figure 9. The failure load values were determined for continuous fibre tows of the basalt and glass following heating at different temperature and times. As mentioned, the residual failure loads measured at $20^{\circ} \mathrm{C}$ following heating are similar to those 
during in-situ heating (Table 1), and therefore the results in Figure 9 are indicative of the high temperature strengths of the basalt and glass tows used in the composites. The values in Figure 9 are expressed as a percentage of the average tow failure load measured at $20^{\circ} \mathrm{C}$, which was $85 \mathrm{~N}$ for the 300 tex basalt tows and $125 \mathrm{~N}$ for the 280 tex glass tows. It should be noted that this difference in tow strength is generally due to the sizing and related friction effects between fibres during testing rather than the single fibre strength, which is higher for basalt [1]. The failure load of both the basalt and glass tows began to decrease following heating above $\sim 250^{\circ} \mathrm{C}$, and fell rapidly with increasing temperature up to $\sim 650^{\circ} \mathrm{C}$ beyond which both fibre types has little residual strength. Figures 10 and 11 compare respectively the tensile strength softening rate and percentage strength retention of the basalt and glass tows with increasing temperature. The values shown are following heating. The tensile softening rate was approximated by assuming the failure load decreased at a linear rate with heating time before reaching the minimum failure load, and is defined as the percentage loss in strength per unit heating time. The results show there was no significant differences in the softening rate and strength loss between the basalt and glass tows.

Based on this information, it is concluded that the inferior fire resistance of the basalt fibre composite was not because it softened and weakened at a faster rate than the glass fibre composite. Instead, the basalt fibre composite was inferior simply because it heated up more rapidly and reached higher temperatures due to the higher emissivity of the basalt. The higher temperatures accelerated the rates of matrix softening, matrix decomposition and fibre weakening which caused the basalt fibre composite to fail sooner than the glass fibre composite.

\section{CONCLUSION}


There is growing interest in the use of basalt fibre as a heat and fire resistant material because of its low thermal conductivity, high oxidation resistance, and high softening and melting temperatures. Also, basalt fibre has higher Young's modulus and tensile strength properties compared to E-glass fibre. This study has shown, however, that a basalt fibre composite has lower tensile fire resistance than an equivalent glass fibre laminate when exposed to the same heat flux representative of a possible fire scenario. Basalt and glass fibre composites softened and decomposed at similar rates at elevated temperature. However, the higher emissivity of basalt fibre composite caused it to heat faster and reach higher temperatures. This caused the basalt composite to undergo softening and decomposition of the polymer matrix and weakening of the fibres at a faster rate, resulting in inferior fire resistance compared to the glass fibre composite under combined tensile loading and one-sided radiant heating.

\section{ACKNOWLEDGMENTS}

This work was undertaken as part of the Composites Fire Performance project of Cooperative Research Centre for Advanced Composite Structures Ltd (CRC-ACS), established and supported under the Australian Government's Cooperative Research Centres Program. One of the authors (T.B.) thanks the CRC-ACS for the provision of a PhD scholarship. The authors thank Robert Ryan and Peter Tkatchyk from RMIT University for technical assistance in the manufacture and testing of the composites, respectively.

\section{REFERENCES}

[1] Singha K. A short review on basalt fiber. International Journal of Textile Science.

2012;1(4):19-28.

[2] Etcheverry M, Barbosa S. Glass fiber reinforced polypropylene mechanical properties enhancement by adhesion improvement. Materials. 2012;5:1084-1113. 
[3] Wei B, Cao H, Song S. Environmental resistance and mechanical performance of basalt and glass fibers. Materials Science and Engineering A. 2010;527:4708-4715.

[4] Gabriele L, Francesco R, Cristiano N, Severino Z. Design and testing innovative materials for passive fire protection. Fire Safety Journal. 2009;44:1103-1109.

[5] Lopresto V, Leone C, De Lorio L. Mechanical characterisation of basalt fibre reinforced plastics. Composites: Part B. 2011;42:717-723.

[6] Cerný M, Glogar P, Goliáš V, Hruška J, Jakeš P, Sucharda Z, Vávrová I. Comparison of mechanical properties and structural changes of continuous basalt and glass fibres at elevated temperatures. Ceramics - Silikáty. 2006;51:82-88.

[7] Allison D. M, Marchand AJ, Morchat R. M. Fire performance of composite materials in ships and offshore structures. Marine Structures. 1991;4(2):129-140.

[8] Bausano JV, Lesko JJ, Case SW. Composite lifetime during combined compressive loading and one-sided simulated fire exposure: characterization and prediction. Composites:

Part A. 2006;37A:1092-1100.

[9] Dao M, Asaro RJ. A study on failure prediction and design criteria for fiber composites under fire degradation. Composites Part A. 1999;30(A):123-131.

[10] Dodds N, Gibson A.G, Dewhurst D, Davies J.M. Fire behaviour of composite laminates. Composites Part A. Composites Part A. 2000;31(A):379-388.

[11] Gibson AG, Wright PNH, Wu YS, Mouritz AP, Mathys Z, Gardiner CP. The integrity of polymer composites during and after fire. Journal of Composite Materials. 2004(38):12831308.

[12] Key CT, Lau J. Constituent based analysis of composite materials subjected to fire conditions. Composites Part A. 2006;37(A):1005-1014.

[13] Liu L, Kardomateas GA, Birman V, Holmes JW, Simitses GJ. Thermal buckling of a heat exposed, axially restrained composite column. Composites Part A. 2006;37(A):972-980. 
[14] Easby RC, Feih S, Konstantis C, La-Delfa G, Urso Miano V, Elmughrabi A, Mouritz AP, Gibson AG. A failure model for phenolic and polyester pultrusions under load in fire. Composites Part A. 2007;39:379-388.

[15] Feih S, Mathys Z, Gibson AG, Mouritz AP. Modelling the tension and compression strengths of polymer laminates in fire. Composites Science and Technology. 2007;67:551564.

[16] Feih S, Mathys Z, Gibson AG, Mouritz AP. Modelling the compression strength of polymer laminates in fire. Composites Part A. 2007;38(A):2354-2365.

[17] Feih S, Mathys Z, Gibson AG, Mouritz AP. Modelling compressive skin failure of sandwich composites in fire. Journal of Sandwich Structures and Materials. 2008;10:217-245. [18] Feih S, Mouritz AP, Mathys Z, Gibson AG. Tensile strength modelling of glass fiberpolymer composites in fire. Journal of Composite Materials. 2007;41:2387-2410. [19] Gibson AG, Wu YS, Evans JT, Mouritz AP. Laminate theory analysis of composites under load in fire. Journal of Composite Materials. 2006;40:639-658.

[20] Feih S, Mouritz AP. Tensile properties of carbon fibres and carbon fibre-polymer composites in fire. Composites Part A. 2012;43(A):768-772.

[21] Burns LA, Feih S, Mouritz AP. Composite properties of carbon-epoxy laminate in fire. Journal of Aircraft. 2010;47:528-533.

[22] Henderson JB, Wiebelt JA, Tant MR. A model for the thermal response of polymer composite materials with experimental verification. Journal of Composite Materials. $1985 ; 17: 579-59$. 


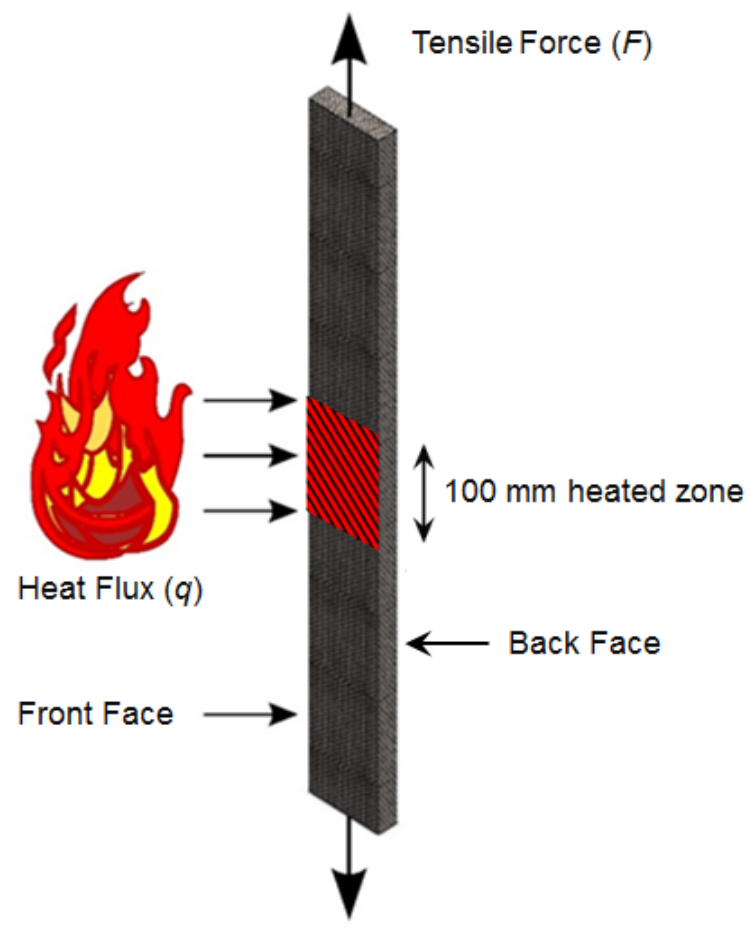

Figure 1. Schematic of the fire structural test which involves subjecting the composite to combined tensile loading and one-sided radiant heating at a constant heat flux representative of a possible fire scenario. 


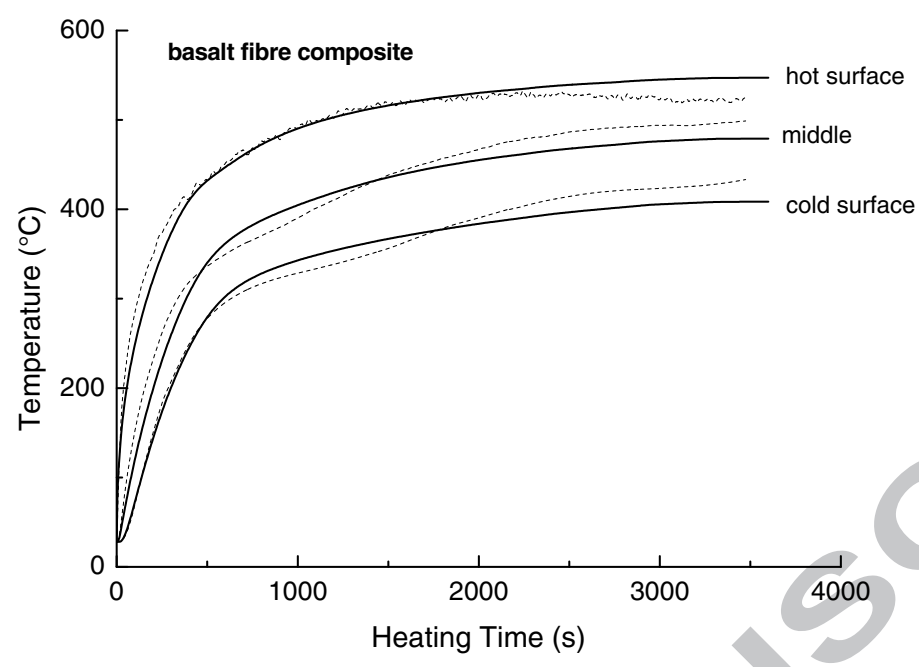

(a)

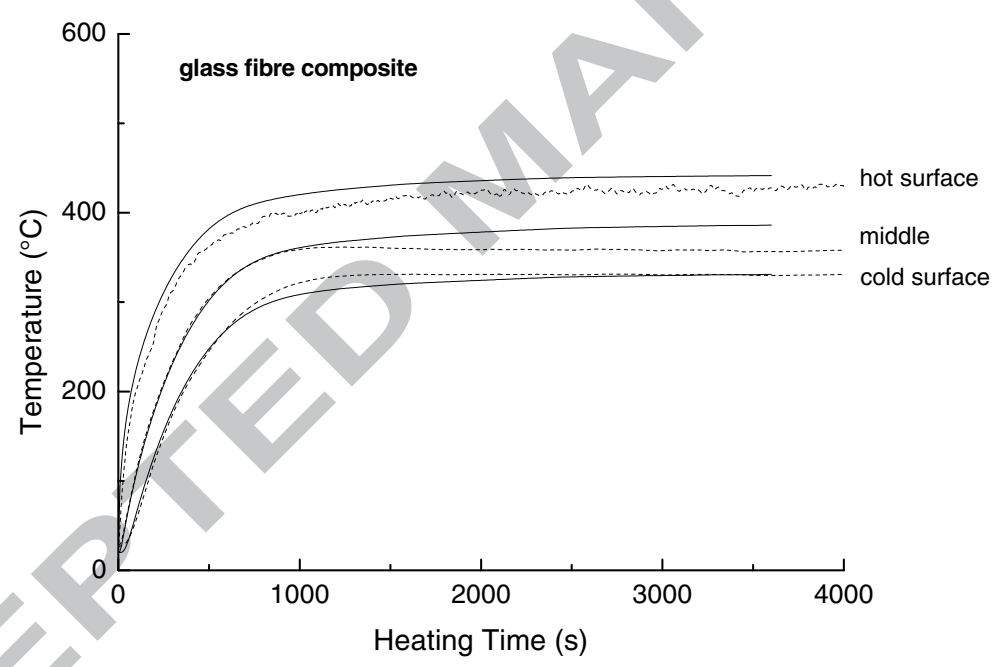

(b)

Figure 2. Temperature-time profiles measured at the hot surface, middle region and cold surface of the (a) basalt fibre composite and (b) glass fibre composite when exposed to the heat flux of $25 \mathrm{~kW} / \mathrm{m}^{2}$. The dashed and solid curves are the measured and calculated profiles, respectively. 


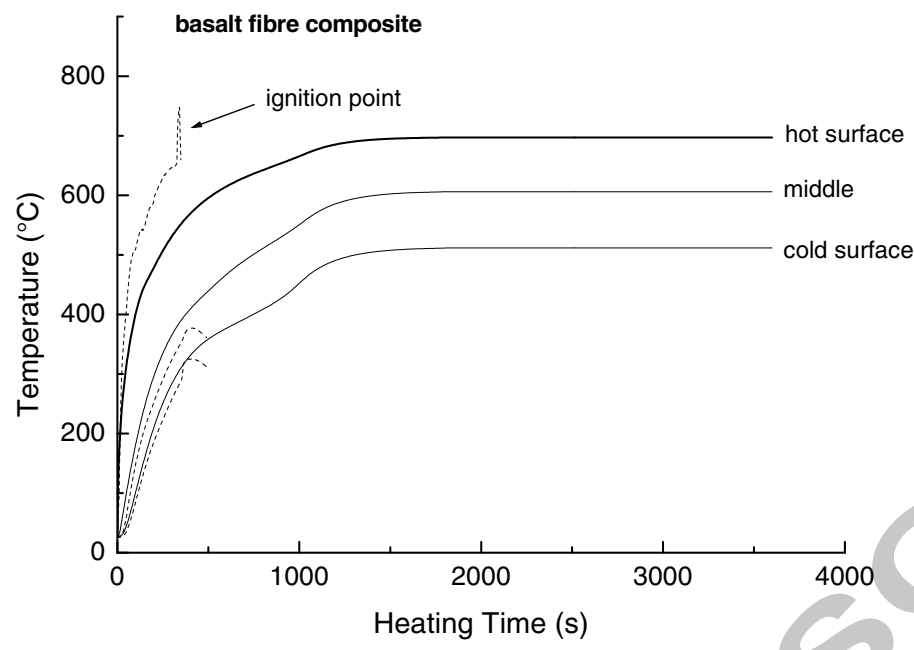

(a)

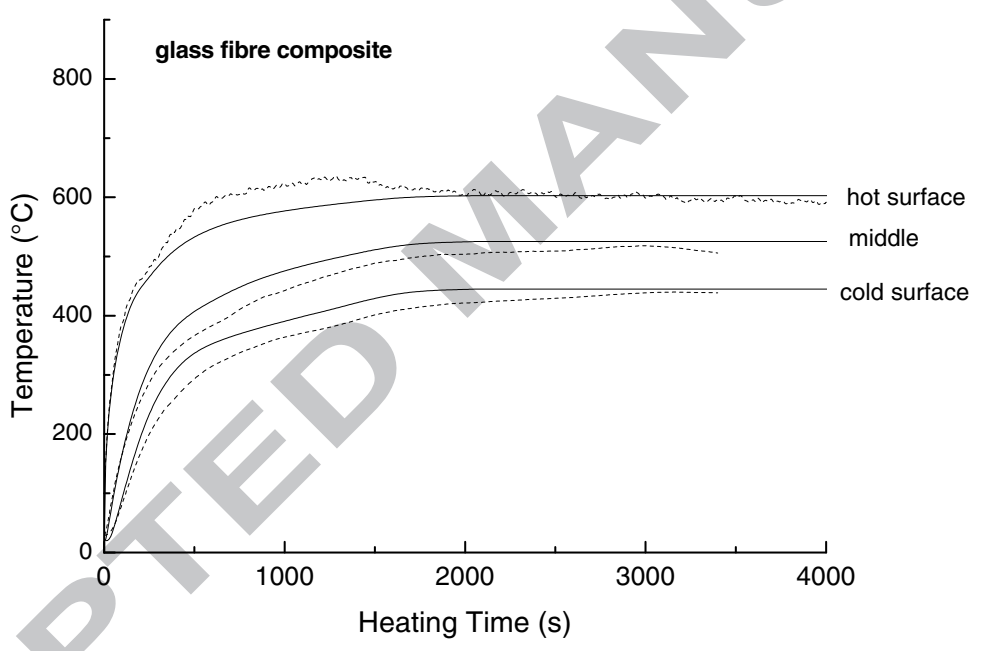

(b)

Figure 3. Temperature-time profiles measured at the hot surface, middle region and cold surface of the (a) basalt fibre composite and (b) glass fibre composite when exposed to the heat flux of $50 \mathrm{~kW} / \mathrm{m}^{2}$. The dashed and solid curves are the measured and calculated profiles, respectively. 


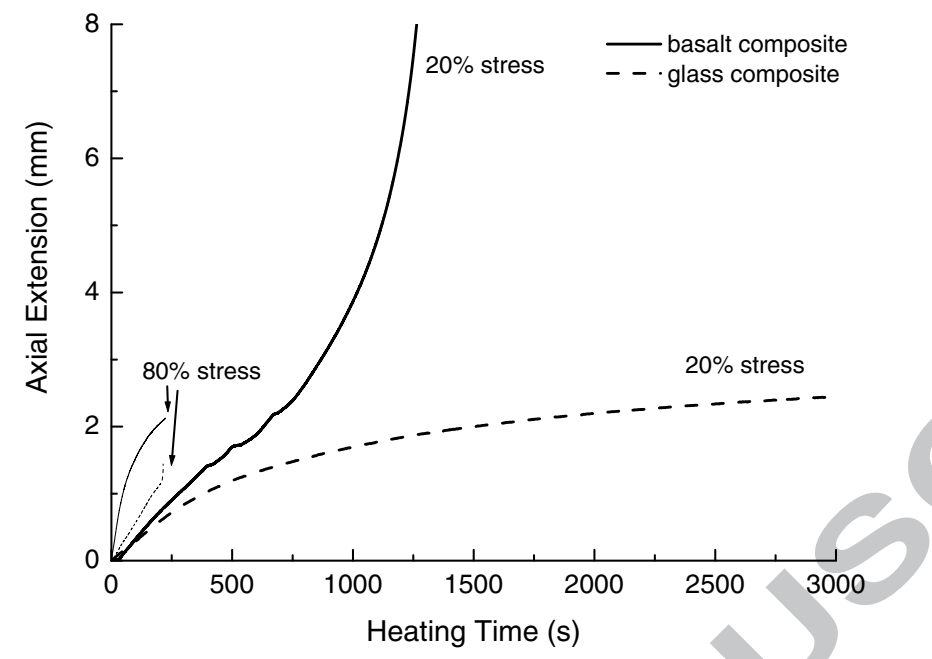

(a)

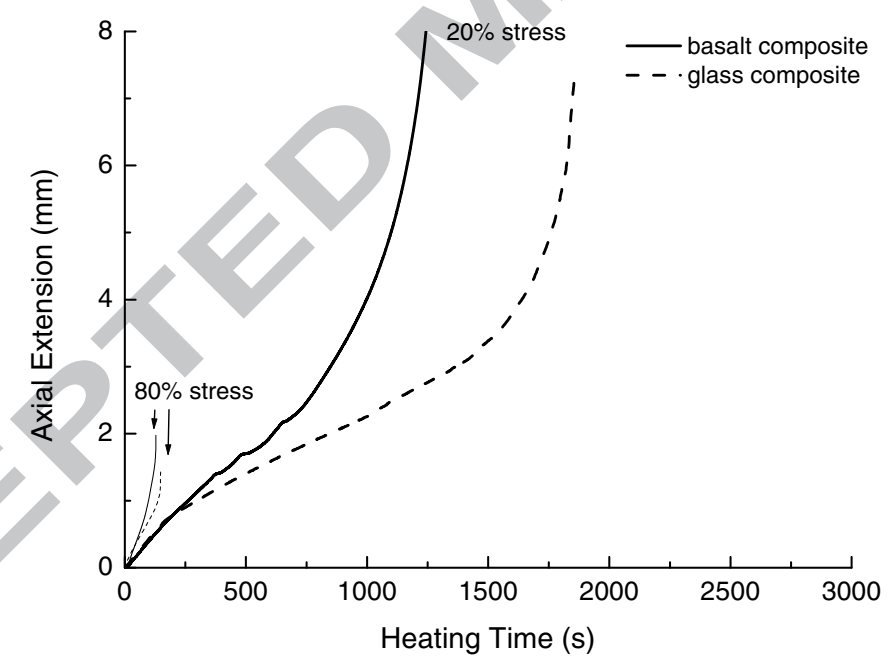

(b) 


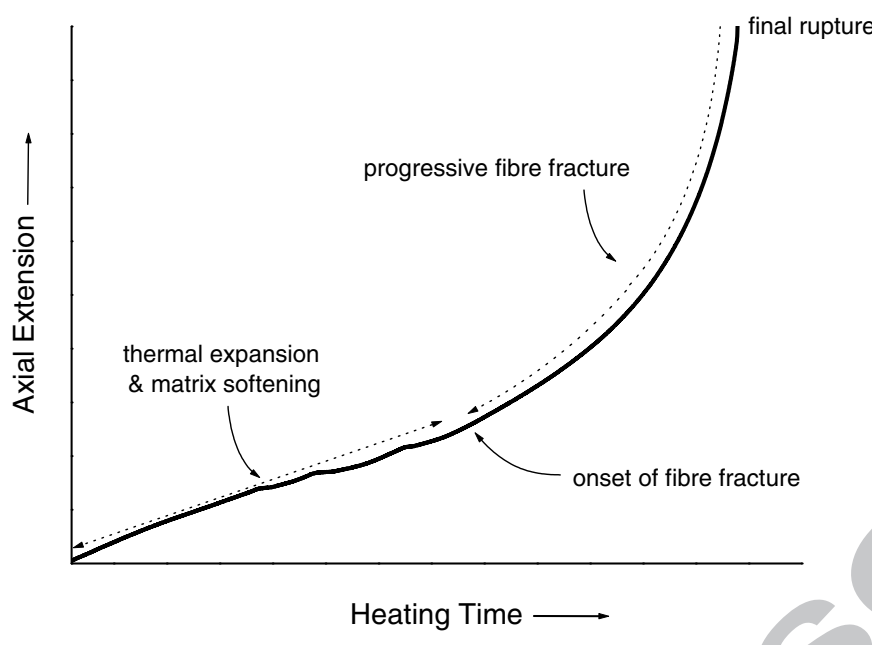

(c)

Figure 4. Effect of heating time on the axial extension of the basalt and glass fibre composites at the heat fluxes of (a) 25 and (b) $50 \mathrm{~kW} / \mathrm{m}^{2}$. The applied tensile stress values are expressed as a percentage of their room temperature tensile failure stress. (c) Schematic showing the softening processes occurring during tensile extension of composites. 


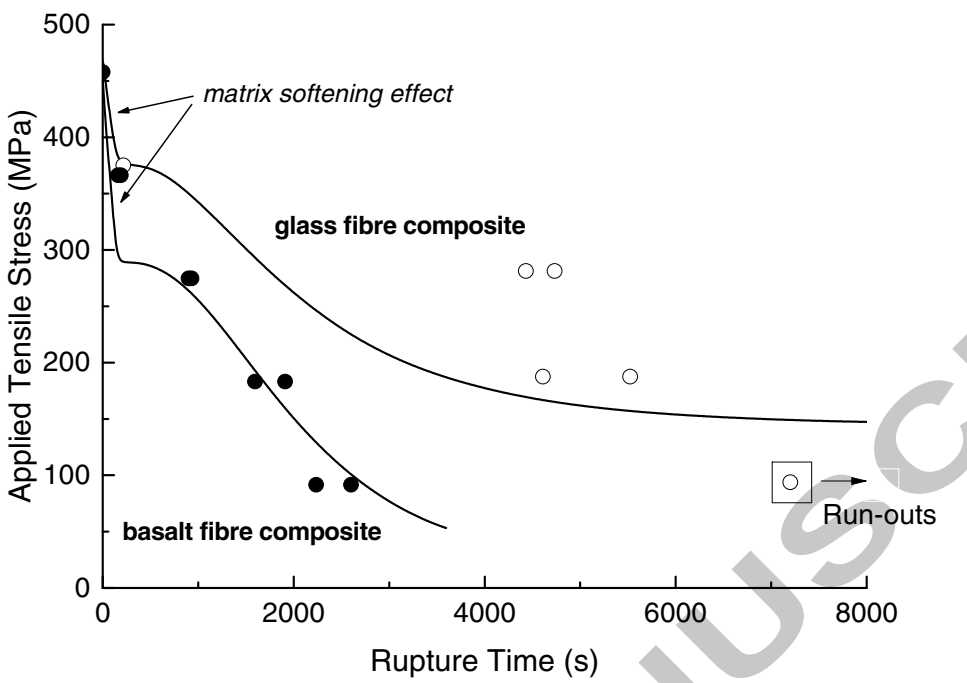

(a)

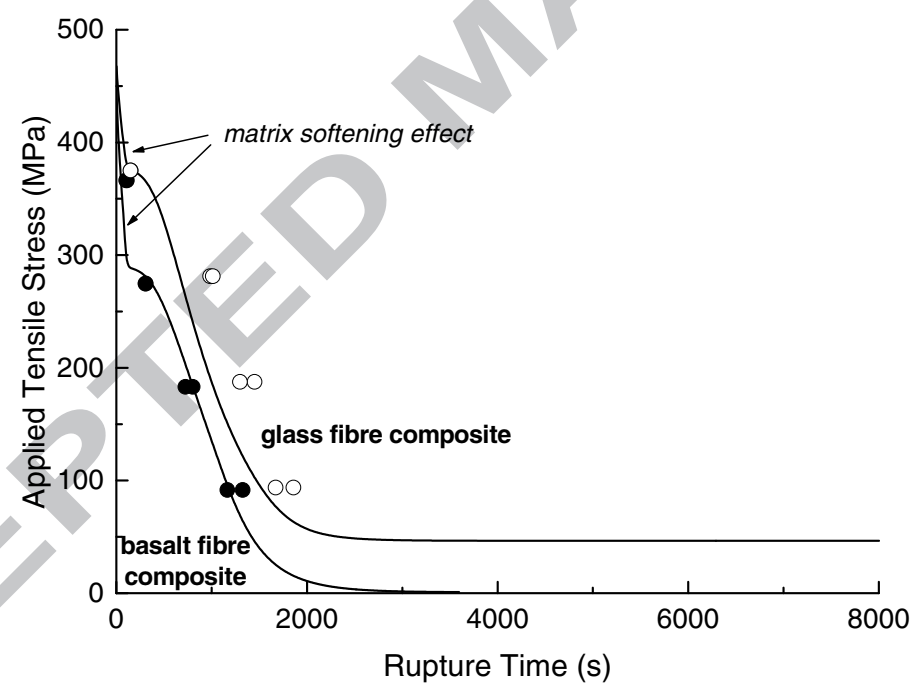

(b)

Figure 5. Effect of constant tensile stress on the rupture times of the basalt and glass fibre composites when exposed to heat fluxes of (a) 25 and (b) $50 \mathrm{~kW} / \mathrm{m}^{2}$. 


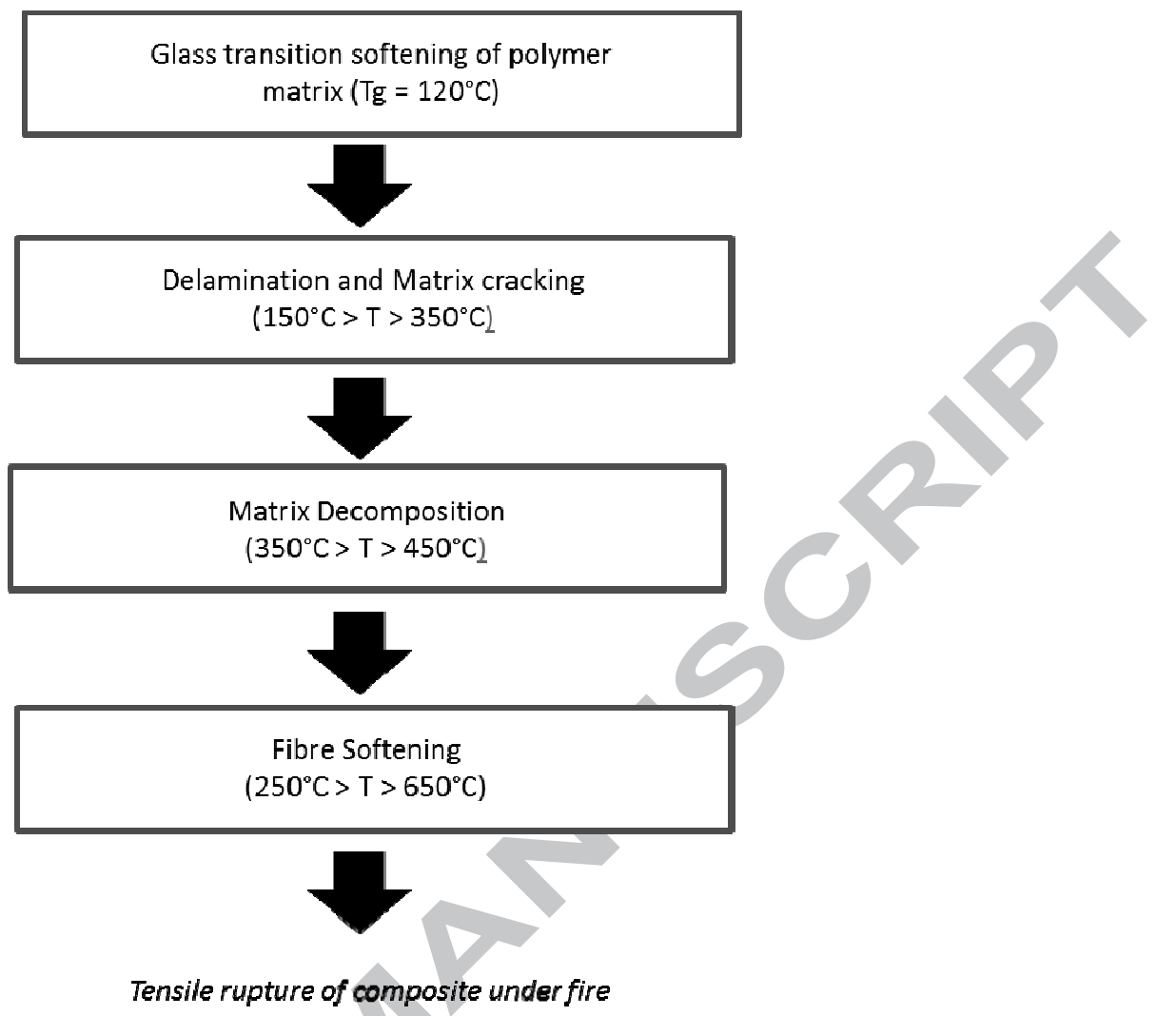

Figure 6. Flowchart indicating the softening processes of basalt and glass fibre composites with increasing temperature. 


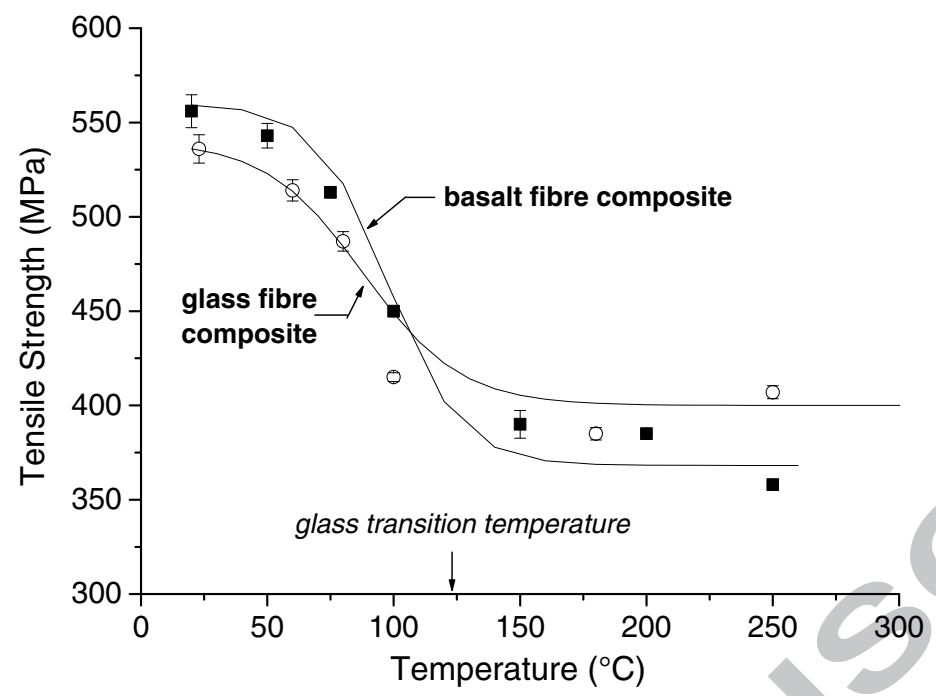

Figure 7. Effect of temperature on the tensile strengths of the basalt and glass fibre composites.

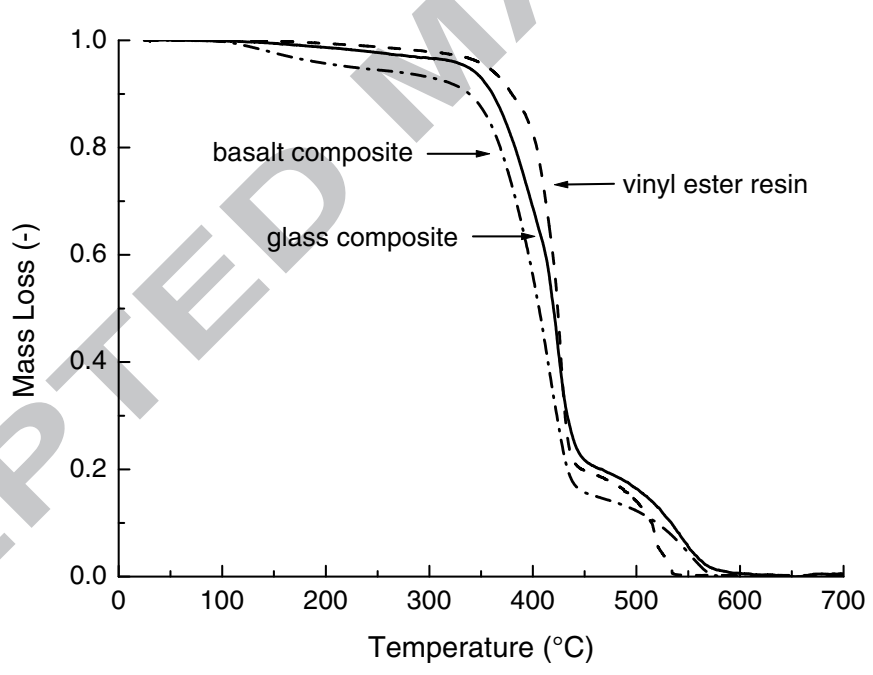

Figure 8. TGA mass loss - temperature curves for the basalt fibre composite, glass fibre composite and unreinforced vinyl ester resin. 


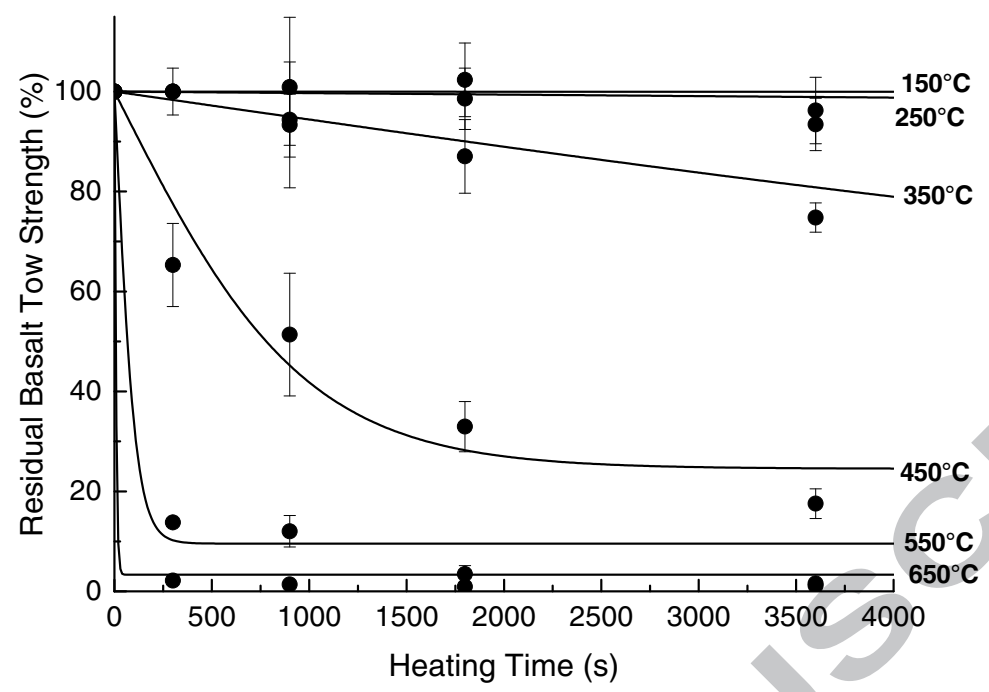

(a)

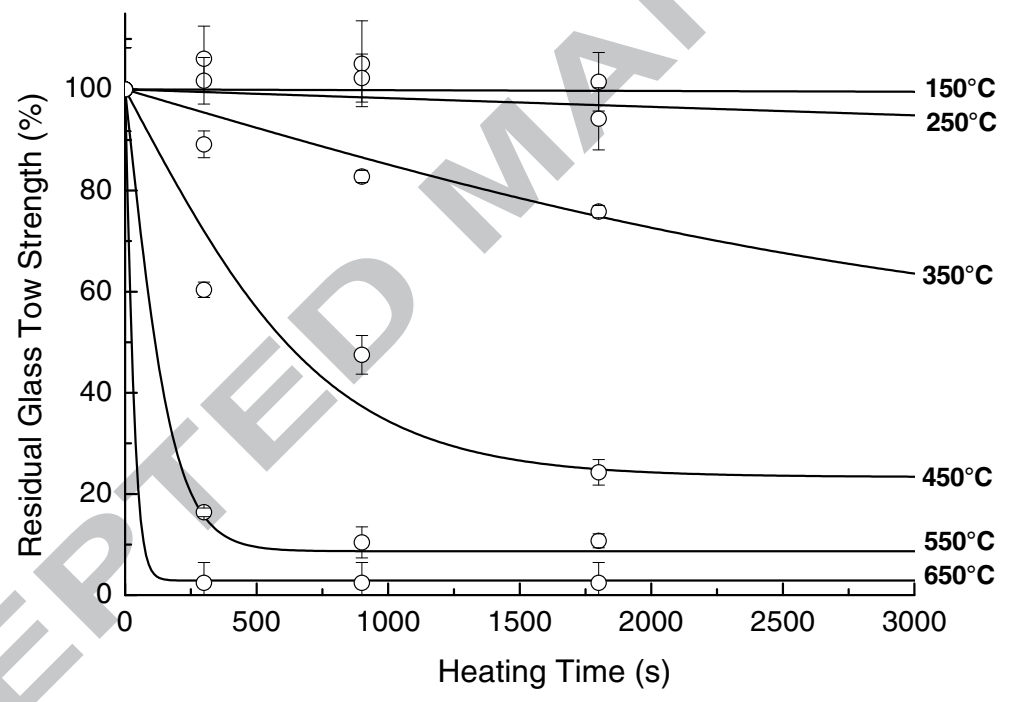

(b)

Figure 9. Effects of temperature and heating time on the percentage tensile failure loads of the (a) basalt tows and (b) glass tows. The values shown are the residual loads measured at $20^{\circ} \mathrm{C}$ following heating. 


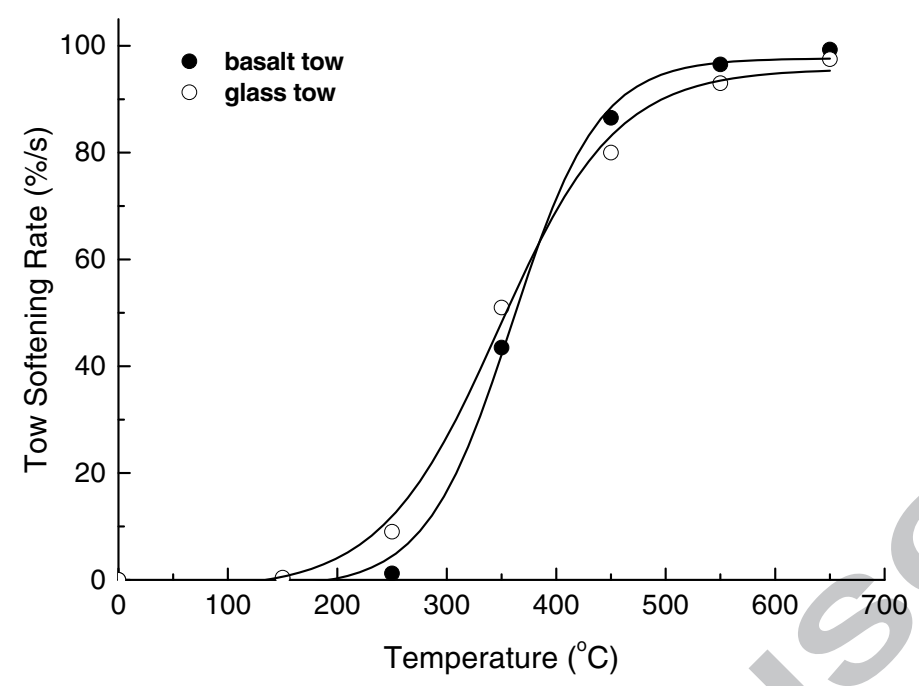

Figure 10. Effect of increasing temperature of the softening rates of the basalt and glass tows. The softening rates were determined using the residual loads measured at $20^{\circ} \mathrm{C}$ following heating.

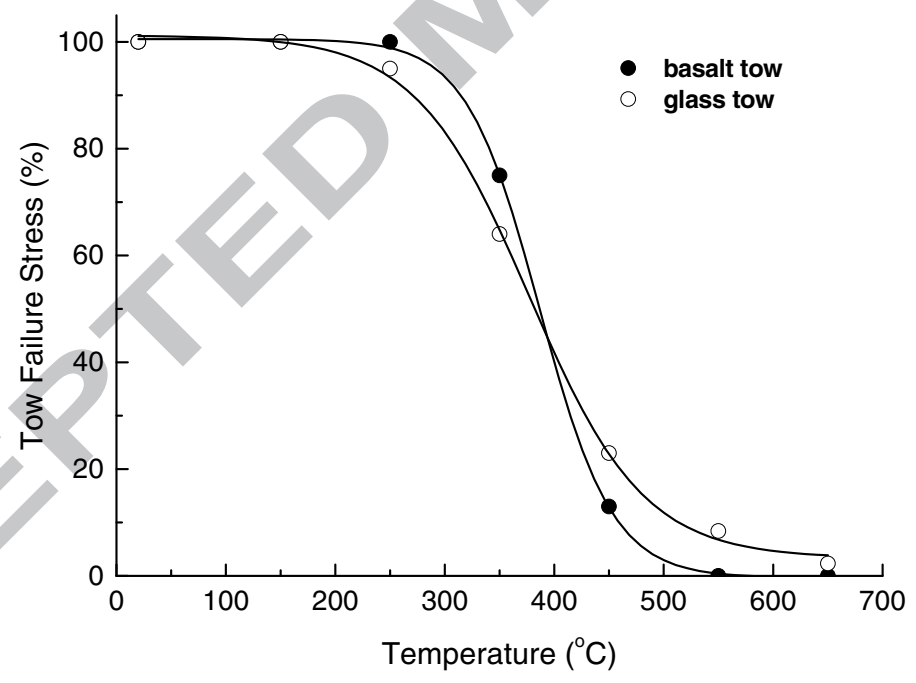

Figure 11. Effect of increasing temperature on the percentage residual strengths of the basalt and glass tows. The tow stress values were measured at $20^{\circ} \mathrm{C}$ following heating at the different temperatures. 
Table 1. Comparison of the tensile failure load of the basalt tows measured at $20^{\circ} \mathrm{C}$ following elevated temperature exposure and measured in-situ at elevated temperature. The percent values give the residual failure load relative to the original (room temperature) failure load.

\begin{tabular}{|c|c|c|}
\hline Temperature & Following Heat Exposure & During Heat Exposure \\
\hline $150^{\circ} \mathrm{C}$ & $85 \mathrm{~N}(100 \%)$ & $82.5 \mathrm{~N}(97 \%)$ \\
$350^{\circ} \mathrm{C}$ & $78.2 \mathrm{~N}(92 \%)$ & $79.1 \mathrm{~N}(93 \%)$ \\
$450^{\circ} \mathrm{C}$ & $57.8 \mathrm{~N}(68 \%)$ & $62.1 \mathrm{~N}(73 \%)$ \\
\hline
\end{tabular}

Table 2. Property data used to determine the fire structural properties of the basalt and fibre glass composites.

\begin{tabular}{|c|c|c|}
\hline Property & $\begin{array}{c}\text { Basalt Fibre } \\
\text { Composite }\end{array}$ & $\begin{array}{c}\text { Glass Fibre } \\
\text { Composite }\end{array}$ \\
\hline Fibre Volume Fraction $\left(\mathrm{V}_{\mathrm{f}}\right)$ & 0.53 & 0.55 \\
\hline Decomposition reaction constant, $\mathrm{A}[1 / \mathrm{s}]$ & $5.59 \times 10^{13}$ & $5.59 \times 10^{13}$ \\
\hline Activation Energy, Q $[\mathrm{J} / \mathrm{kg}$ mol] & 212705 & 212705 \\
\hline Order of decomposition reaction, $\mathrm{n}$ & 1 & 1 \\
\hline Thermal conductivity [W/mK] $\left(60-300^{\circ} \mathrm{C}\right)$ & 0.41 & 0.43 \\
\hline Remaining resin mass fraction $[\%]$ & 3.0 & 3.0 \\
\hline Resin strength at room temperature $[\mathrm{MPa}]$ & 69.0 & 1.4 \\
\hline Resin strength at 300 ${ }^{\circ} \mathrm{C}[\mathrm{MPa}]$ & 1.4 & 1.0 \\
\hline Load transfer factor at $20^{\circ} \mathrm{C}, \phi_{\mathrm{T}}$ & 1.0 & 0.8 \\
\hline Load transfer factor at $300^{\circ} \mathrm{C}, \phi_{\mathrm{T}}$ & 0.72 & 0.65 \\
\hline Emissivity at $20^{\circ} \mathrm{C}$ & 0.92 & 347 \\
\hline Fibre Bundle Strength, $\sigma_{\mathrm{f}(0)}[\mathrm{MPa}]$ & 1454 & 390 \\
\hline $\begin{array}{c}\text { Fitted fibre bundle } 50 \% \text { strength loss temperature, } \\
\mathrm{T}_{50 \%}\left[{ }^{\circ} \mathrm{C}\right]\end{array}$ & $390.83 \times 10^{-3}$ \\
\hline $\begin{array}{c}\text { Fitted empirical constant from fibre bundle data, } \\
\mathrm{p}_{\mathrm{fb}}\left[{ }^{\circ} \mathrm{C}^{-1}\right]\end{array}$ & $1.62 \times 10^{-2}$ & $1.81 \times 10^{-6}$ \\
\hline Fitted fibre bundle strength loss rate, $\mathrm{k}_{1}\left[\mathrm{~s}^{-1}\right]$ & $8.36 \times 10^{-6}$ & $1.45 \times 10^{-2}$ \\
\hline Fitted fibre bundle strength reduction parameter, \\
$\mathrm{k}_{2}\left[{ }^{\circ} \mathrm{C}^{-1}\right]$
\end{tabular}

